\title{
CONTACT-INDUCED TYPOlOGicAl CHANGE
}

\author{
Sarah Grey Thomason \\ University of Michigan
}

1. Introduction. It is easy to show that contact-induced change can have a profound effect on the typological profile of the receiving language. Probably the most obvious examples, and also the ones that are easiest to find, are changes in basic sentential word order. These are especially striking because it is word order features that have attracted the most attention in the typological literature, starting with the famous 1963 article by Greenberg that moved typology into the mainstream of linguistic research. But word order features - or, more generally, morpheme order features - are by no means the only parts of language structure that have been transformed under the influence of other languages. Contact-induced changes have also affected the typological character of morphological, phonological, lexical semantic, and discourse systems in a wide variety of languages.

This article surveys contact-induced typological changes and shows where and how different degrees of change correlate with different social conditions. After some introductory comments on the contact conditions in which typological change is likely to happen (§2) and on the problem of determining whether a given change is typologically significant or not (§3), I will discuss and exemplify immediate typological effects $(\S 4)$ and delayed typological effects (§5). Finally, I will consider the question of whether or not language mixing constitutes contact-induced typological change $(\S 6)$. The article ends with a brief conclusion $(\S 7)$.

2. When Should We EXPECT TYPOlOGicAl CHANGE AS A RESUlt of CONTACT? The first step in discussing contact-induced typological change is to sketch the circumstances under which it is likely to occur. The crucial point-hardly an astonishing one - is that intense contact is more likely than casual contact to result in typological restructuring of the receiving language. The question of what counts as intense contact (an admittedly vague term) depends on the perspective: the expected results differ according to whether the situation is one of borrowing, where fluent speakers of the receiving language adopt features from the source language, or imperfect learning, where native speakers of the source language have learned the receiving language imperfectly and incorporate their learners' errors into their version of it. The latter type of situation usually, though not always, involves language shift; for convenience, I will refer to these as shift situations. The expected linguistic results are as different as the processes: in borrowing situations, the first interference features to turn up in the receiving language are loanwords, followed (if contact becomes intense enough) by structural features, especially in the phonology and syntax. In shift situations, by contrast, the first interference comprises phonological and syntactic features, and sometimes there are very few loanwords at any stage.

Intensity of contact in a borrowing situation depends largely, though not entirely, on the level of bilingualism (number of bilinguals, degree of fluency) among borrowing-language speakers: more bilinguals, more intensity, more interference. If the level of bilingualism among borrowing-language speakers is low, then interference features are likely to be confined to loanwords and minor structural features that do not disrupt the typological patterns 
of the borrowing language. Only if there are many bilinguals, and great cultural pressure on borrowing-language speakers, are major typological changes likely to occur. But in addition, in borrowing situations the degree of typological distance between source language and receiving language influences the kinds of features that are likely to be transferred; so one sometimes finds typologically congruent interference features being transferred at relatively low levels of bilingualism.

Intensity of contact in a shift situation depends to a considerable extent, but also not entirely, on the numbers of shifting speakers compared to the numbers of target-language speakers: the larger the shifting group, the more interference features there are likely to be. In a shift situation, because interference features are introduced by the imperfect learners themselves, the very first interference features to appear in the receiving language are likely to be typologically disruptive, because the learners will carry over features from their native language and fail to learn certain features of the target language. Indeed, structural features shared by the source and receiving languages are less likely to present learning problems for the shifting speakers, so these target-language features are more likely to be learned correctly.

In shift situations, then, intense contact is not needed for typologically disruptive interference features to appear in individual learners' versions of a target language. But it is needed for such features to be incorporated in an integrated version of the target language that is spoken both by members of the shifting group and their descendants and by original target-language speakers and their descendants: unless there are a great many shifting speakers relative to the number of original target-language speakers, only a subset of the shifting speakers' errors are likely to be adopted by original target language speakers. Of course, it sometimes happens that shifting speakers remain a partially isolated subgroup of the target language speech community, without integrating into the larger community; in such cases their version of the target language may well retain most of the original shifting group's interference features.

This outline of the basic split between borrowing and shift situations, although it applies neatly in many cases of contact-induced change, is difficult or impossible to sort out for a sizable number of contact situations, in the absence of explicit social information about the nature of contact. One problem is that shift-induced interference and borrowing often occur in one and the same contact situation; another is that areal phenomena involving several languages may arise through a complex combination of processes, some involving imperfect learning and some involving borrowing.

But perhaps the most important caveat is that NECESSARY conditions for contact-induced change are by no means the same thing as SUFFICIENT conditions for change, especially in potential borrowing situations: sometimes, even in the most intense contact situations, with extensive bilingualism in (say) a minority group and with extreme cultural pressure, speakers of the minority language fail, or refuse, to borrow anything much from the dominant language. When deciding whether to expect typological change to result from contact, therefore, we must always keep in mind that our expectations may be disappointed, even when the basic social setting seems outwardly ideal. Speakers' attitudes are unpredictable, and attitudinal factors can and do play a major role in this domain.

3. What counts as typological Change? Before we can survey the kinds of typological change caused by language contact, we must identify the object of study. Clearly, 
not all contact-induced changes alter the typology of the receiving language. Some of them are typologically inert: either they fit neatly into the typological patterns of the reciving language, or they are too minor to constitute a significant typological change. A typical example is the introduction of a loanword like Persian shah into English. The only segments that survive in the English pronunciation, the $[\check{\mathrm{s}}]$ and the $[\mathrm{a}]$, already have close phonetic analogues in English; and, though a word-final stressed [a] is unusual in an English word, it does occur occasionally (e.g. in the colloquial address form $p a$ for 'father'). Similarly, the borrowed word asparagus is too long for a native morpheme, but is phonologically ordinary for an English word. And a great many other loanwords, such as reindeer and animal, don't clash even with minor phonotactic patterns.

A more interesting example is the German name Bach, which some English speakers pronounce with a German dorso-uvular fricative $[\mathrm{X}]$ instead of an anglicized [k]. The phone $[\mathrm{X}]$ is foreign to English, but it is confined to this one word, so its presence can hardly be said to have transformed English phonology. And even if there were more examples of [X], they would not disrupt the English phonological system significantly, because the distinctive features specifying voicelessness and fricativeness are already needed to describe native English consonant phonemes. Adding $[\mathrm{X}]$ would necessitate no changes in the basic feature structure - only in the instantiation of the features in a previously unused combination.

Comparable examples can be found in the syntax, where an increase in the frequency of one of several possible word orders, under the influence of a language in which one of the patterns is basic, alters the overall word order typology only slightly. There are numerous examples of this sort in the literature. To mention just one, the Waikurúan language Kadiwéu of Brazil has quite free word order - OVS, VOS, SOV, OSV, VSO, and SVO word orders are all possible and well attested in the language. But Kadiwéu/Portuguese bilinguals tend to prefer SVO word order, which matches Portuguese (Sandalo 1995; and see, as prominent examples among many other sources, Pfaff 1979 and Silva-Corvalán 1994 for discussion of other instances in which bilinguals favor surface patterns that are common to both languages). If all the possible word orders continue to be used in such a case, the change in the frequency of use of one particular pattern has no drastic overall effect on the language.

Other contact-induced changes, of course, do have clear typological effects. The introduction into English of French words like very, with initial voiced fricatives, contributed to the phonemicization of the formerly allophonic distinction between voiced and voiceless fricatives, though several internal changes also played a role in this process; and the very large number of French and Latin loanwords into Middle English obscured and ultimately destroyed the inherited Germanic pattern of fixed initial stress.

The shift in Ethiopic Semitic languages from verb-initial to verb-final word order, together with other typical characteristics of verb-final syntax, also altered the languages' syntactic typology. The starting point was a typically Semitic structure with VSO sentential word order, auxiliary preceding main verb, and relative clause following head noun; after the Semitic languages of Ethiopia came under the influence of indigenous Cushitic languages, some of whose speakers shifted to Semitic, the pattern changed to SOV, main verb preceding auxiliary, and relative clause preceding head noun. (For a detailed discussion of this case, see especially Leslau 1945, 1952, but also Moreno 1948, Hetzron 1954, and Little 1974.) In a related change, prepositional phrases were altered by the addition of postpositions, yield- 
ing a construction type Preposition-NP-Postposition - identical neither to the prepositional Semitic pattern nor to the postpositional Cushitic pattern, but rather a combination of the two. This same basic change can be seen also in the addition of a negative perfect suffix to a construction already containing a Semitic negative perfect prefix, resulting in a verb form with a negative perfect circumfix.

Nor were Cushitic-induced typological changes in the Semitic languages of Ethiopia confined to morpheme order features: the typical Semitic pattern in which coördination and subordination were expressed primarily by finite verbs in coördinate and subordinate clauses was replaced by typically Cushitic gerund constructions; the dual number was lost almost completely; a new labialized dorsal stop series was introduced; and the inherited Semitic pharyngealized emphatic consonants were replaced by glottalized consonants. In this case there is no doubt that significant typological change has occurred, and the link to contactthe imperfect learning of Semitic by shifting Cushitic speakers - is firmly established. This is the sort of case for which Malcolm Ross has proposed the label 'metatypy' (1996:182)

It is easy, then, to identify clear cases on both sides of the typological change/no typological change boundary, but it's also necessary to recognize a large area in the middle where reasonable people might differ on the question of whether contact has resulted in significant typological change or not. Changes like the addition of a new phoneme / X/ in the German name Bach to some varieties of English and the increase in the frequency of SVO word order in Kadiwéu-Portuguese bilinguals' speech fall into the fuzzy boundary area. In the rest of this essay I will concentrate on clear cases of typological change through contact.

4. Immediate typological efFects. The word 'immediate' in the title of this section is not meant to imply that any contact-induced change happens overnight, because no linguistic change is that abrupt. In real life, one or more speakers innovate, and those innovations spread through the innovators' speech and the community's speech in various ways and at various rates, with extensive variation in both individuals and the community as a whole during the process. The distinction I have in mind, in this section and the next, is rather different: some contact-induced changes, once implemented in an individual or a community, have an immediate typological effect (this section); others, though they may be typologically insignificant at first, trigger a sequence of internal changes that ultimately results in significant typological change $(\S 4)$.

Although the language contact literature is full of descriptions of changes in the moststudied linguistic subsystems, relatively little has been written about contact-induced changes in other areas, notably lexical semantics. It is possible, however, to find changes in the lessstudied subsystems too; one example from lexical semantics is the restriction of feminine gender to human females in the dialect of the Indic language Urdu that is spoken in Kupwar, under the influence of a Dravidian language, Kannada.

Here are a few typical examples of immediate typological effects of contact-induced phonological changes. When, as a result of the influence of Caucasian languages, the Iranian language Ossetic acquired a new glottalized stop series (Comrie 1981:167, 171), the typological structure of its consonant inventory was significantly altered. The merger of the two Greek interdental fricatives with other phonemes (e.g. dental stops) in Asia Minor Greek, a result of Turkish influence (Dawkins 1916:44, 76, 77) sharply reduced the fricative inventory. Dramatic morphophonemic changes such as the loss of vowel harmony in some dialects of 
the Turkic language Uzbek, under the influence of the Iranian language Tadzhik (Comrie 1981:51f., 56), and the mirror-image development of partial vowel harmony in some dialects of Asia Minor Greek under Turkish influence (Dawkins 1916:47, 68) are fairly easy to find in intimate contact situations. Contact can also cause changes in syllable structure constraints; an example is the loss of syllable-initial consonant clusters, apparently due to Kwakiutl (Wakashan) influence (Thompson 1979:732), in the Salishan language Comox, a member of a family which otherwise boasts some of the most elaborate consonant clusters in the world.

Comparably dramatic immediate effects can be found in contact-induced changes in the morphology and syntax of a wide variety of languages, changes that bring about significant alterations in the grammar of particular subsystems. Examples are the development of agglutinative case + number suffixation on nouns in Asia Minor Greek through borrowing from Turkish, replacing inherited flexional Indo-European case/number inflection (Dawkins 1916:114); the emergence of nine new agglutinative cases in Ossetic, under Caucasian influence (Comrie 1981:171); possessive pronominal suffixes in the Dravidian language Brahui, through borrowing from the neighboring Iranian language Balochi or possibly from a northwestern Indic language (Emeneau 1980 [1962]:60); conjugated negation via a suffix placed between the verb and the subject marker in the Indic language Marathi (under Dravidian influence; Klaiman 1977:311); the new inclusive/exclusive 'we' distinction in the Urdu dialect spoken in Kupwar (via borrowing from Kannada and/or Marathi-Gumperz \& Wilson 1971); loss of the inclusive/exclusive 'we' distinction in Brahui, under Balochi influence (Emeneau 1980 [1962]:56); the partial loss of preverbs in a variety of American Hungarian, a complex change resulting in part from attrition processes in language death and in part from borrowing from English (Fenyvesi 1994); the development of rigid SOV word order in the Chinese language Wutun, under the influence of Anduo Tibetan (Li 1983:32); the loss of gender agreement in noun modifiers in Kupwar dialects of Marathi and Urdu under the influence of Kannada (Gumperz \& Wilson 1971); and the development of numeral classifiers in the Dravidian languages Kui-Kuwi, Kurukh, and Malto under the influence of Bengali, Assamese, and other eastern Indic languages (Emeneau 1980 [1965]:131).

The examples above are presented as a scattershot list, to provide a glimpse of the variety of contact-induced morphosyntactic changes in the world's languages. But plucking an instance here and an instance there from a given language may suggest - erroneously - that a typologically significant change might be isolated in the linguistic system of a particular language. Such isolation is unlikely: a language is much more likely to have undergone either a whole range of contact-induced typological changes in its various subsystems or none.

A more realistic balance can be found in any of a number of case studies of particular language contact situations - among them the studies from which the scattershot examples were drawn. Consider, to take just one instance, Ross's description (1996:187-202) of two striking cases from Papua New Guinea: Takia and Maisin, two languages of the Western Oceanic branch of Austronesian which have undergone extensive interference from non-Austronesian languages of New Guinea. Among the interference features shared by Takia and Maisin are rigid verb-final word order in clauses, lack of articles, postpositions instead of prepositions, preposed instead of postposed possessor noun phrases, and 'chains of coordinate dependent clauses terminating with an independent clause' (p. 202). Maisin has several other Papuan features in addition to these, including a set of tense/aspect/mood markers that occur in the position (though not with the exact functions) of tense/aspect/mood markers 
in nearby non-Austronesian New Guinea languages (p. 196). Ross does not discuss changes in the phonology of Takia and Maisin, but in fact intense contact is likely to result in both phonological and morphosyntactic change; to give just one instance, note the extensive typological changes that took place in Asia Minor Greek under Turkish influence, as described in Dawkins 1916 (and, for a brief synopsis of this case, see the report in Thomason \& Kaufman 1988).

It is possible that some of these changes, especially those in the morphology and syntax, were later stages in a chain reaction which, though originally set off by contact, proceeded by internally induced change later on. To decide whether they were immediate or delayed effects of contact, it would be necessary to know precisely which bits of the relevant linguistic structures are linked in such a way that a contact-induced change in one place might trigger an internal change in another. We already know about linkages in aspects of morpheme order, since certain patterns have been shown to co-occur in a nonrandom way; morphemeorder changes are therefore good candidates for delayed typological changes. But in most instances, because of the lack of ancient documentation, we do not know - even for this muchstudied feature, much less for others - whether a set of morpheme-order changes happened more or less all at once (so that each change was a direct instance of interference) or in a chain reaction (so that only the first change in the chain was an immediate effect of language contact). This difficulty is easier to describe than to resolve, so I will leave it as a cautionary note and move on to a consideration of contact-induced changes that seem fairly clearly chained.

5. Delayed typological effects. Delayed typological effects occur when the first in a series of changes is typologically minor or irrelevant, but later changes in the series lead to significant typological change. That is, there is a snowball effect: the first change triggers the next, which triggers the next, and so forth. Assuming that only the initial change in the series is caused directly by contact, a question arises: how many of the changes in the series are contact-induced? Only the first one, or all the later ones as well? The answer to this question depends on one's definition of contact-induced change. Here is mine: a change is caused at least in part by language contact if it is less likely to have occurred outside a particular contact situation. Note that this definition includes both actual interference from one language into another and changes like attrition in language death, which are caused by contact but are not interference features per se. According to this definition, the entire series of changes in a chain reaction would be contact-induced, since none of them would have been as likely to occur outside the contact situation that caused the initial change.

One of the most common, or at least best-attested, contact-induced chain reactions concerns the syntactic expression of subordination. One typical set of changes took place in Asiatic Eskimo. The initial change, a direct influence from Chukchi, was the borrowing of conjunctions into Eskimo (Menovščikov 1969:124-130). Function words are frequently borrowed, and the conjunctions themselves would not disrupt the typology of clause combining. Later, however, as a result of this initial change, Eskimo replaced native gerund and other non-finite verbal constructions with constructions of conjunction + finite clause. Similar change processes led to the development of finite subordinate clauses in Brahui, starting with a subordinating conjunction ki borrowed from Balochi (Emeneau 1980 [1962]:59), and in Azerbaidzhani, in which inherited Turkic participial or gerund constructions were replaced 
by subordinating conjunctions and finite verbs (Comrie 1981:84).

In the phonology, delayed typological change can be exemplified by at least one case of tonogenesis and one apparent case of its reverse. The process of tonogenesis in Vietnamese probably began - though precise documentation is lacking - with the introduction of large numbers of Chinese loanwords during periods of very strong Chinese influence on the culture and language of Vietnam. It's likely that these loanwords were nativized at first, entering the nontonal borrowing language without their tones and with segmental alterations as well to fit native (Pre-)Vietnamese phonological structure. But, as is typical with patterns of contact-induced change, an increase in bilingualism among borrowing-language speakers presumably led to the abandonment of nativization as a strategy, and new Chinese loanwords would then be nativized less drastically or not at all - in particular, keeping their tones. The later changes which led to the emergence of Vietnamese as a full-blown tonal language were internal, involving consonant losses and mergers that left traces of the original consonant distinctions in (originally consonant-induced) pitch distinctions on the neighboring vowels. A similar change, but in reverse, may well have led to the loss of the tonal system of Swahili: masses of loanwords from the nontonal language Arabic into Swahili, which as a Bantu language would have inherited tones, would eventually have led to the abandonment of tones even in native Swahili words.

I know of a few other examples that seem to fit into this category of typological change through language contact, but clear examples of delayed typological effects are certainly less common than changes that seem to fit into the immediate category. As noted above, some changes that look as if they must have had immediate typological effects on the receiving language may in fact have had delayed effects instead - a chain reaction often can't be detected after the fact, given the lack of adequate documentation for the vast majority of linguistic changes, contact-induced as well as internally-motivated. The difficulty of establishing large numbers of examples, however, does not make the distinction between immediate and delayed effects trivial; a systematic search for new examples of delayed typological effects is likely to be fruitful.

6. Is LANGUAGE MiXing TyPOLOGICAL Change? So far I have said nothing about the most striking of all typological effects of language contact - namely, the typology of mixed languages, which are usually or always typologically unlike all of their source languages. Mixed languages fall into three general categories (Thomason 1997): pidgins, creoles, and bilingual mixtures. Most pidgins and creoles draw their lexicon primarily from a single source language, the lexifier, and their grammars do not come from that source language or from any other single language; the grammar of a typical pidgin or creole is in fact quite different from the grammar of any of the source languages. Bilingual mixtures emerge, as the name suggests, in a context of bilingualism between two groups in contact, and several combinations of components are attested in the small set of well-understood cases: lexicon from one source and grammar from the other, as in the Media Lengua, a Spanish/Quechua mixture (Muysken 1997), or Ma'a, a Cushitic/Bantu mixture (Mous 1994); noun phrases from one language and verb phrases and sentential syntax from the other, as in Michif, a French/Cree mixture (Bakker \& Papen 1997); lexicon and grammar mostly from one source but finite verb morphology from the other, as in Mednyj Aleut, an Aleut/Russian mixture (Menovščikov 1969); and so forth. 
It is easy to prove that mixed languages of all these types do not match any of their source languages typologically. In pidgins and creoles, which arise in a context where, and indeed usually because, there is insufficient mutual bi-/multilingualism, the phonology and morphosyntax are typically quite unlike those of the lexifier language (though not always, in the case of the phonology); they may be a better typological fit with the other source languages, but their relative (and often absolute) poverty in inflectional morphology distinguishes their typological profile sharply from those of many or most of their source languages.

Bilingual mixed languages, which arise from combining subsystems of two languages, show little or no distortion of material drawn from the source languages, but the structure as a whole does not match either source language. In Mednyj Aleut, for instance, features of verb inflection such as preposed negation, gender in subject markers, and flexional morphology do not resemble Aleut structure at all, while other structural features, such as polysynthetic morphology (outside the finite verb morphology), ergative noun morphology, and dual inflection in nouns are typologically divergent from Russian. Similarly, Michif noun phrases have French phonological, morphological, and syntactic features - among them vowel nasalization, masculine/feminine gender agreement, and lexical adjectives - that do not fit Algonquian typology, while Michif verb phrases have Cree features like heavy agglutination, an animate/inanimate gender distinction, and obviative marking, which do not fit French typology.

The problem here, then, is not a question of whether or not language contact has led to the emergence of languages with typologically divergent structures, by comparison to their various source languages. Rather, the question is whether we are looking at language change in these cases: if the process by which mixed languages arise is not language change, then these are not cases of contact-induced typological CHANGE. For creoles, at least, the answer depends on which theory of creole genesis one adopts (focusing solely on creoles that arise without a well-established pidgin stage, as opposed to creoles that arise as nativizations of pre-existing pidgins): if one accepts the currently popular theory of gradual creolization, according to which each new contingent of imported slaves learned a variety of the lexifier language slightly more divergent from the lexifier language than the variety spoken by the immediately preceding contingent, then creolization is a process of repeated shift-induced interference and therefore a process of language change. But if the competing theories of abrupt creolization are correct, so that creole genesis is a process of creation of a new language through a kind of negotiation among members of a new contact community, then characterizing it as a process of change from a previously existing language seems inappropriate. To make the issue even more complex, note that there is no reason to assume that all creoles arose in the same way, so that the gradualist hypothesis might well be valid for some but the abrupt hypothesis for others. One example of definitely abrupt creole genesisbecause the original population was not added to - is Pitcairnese, which arose on Pitcairn Island after nine English-speaking Bounty mutineers and sixteen Polynesians took refuge there in 1790 .

As for pidgins, a theory of gradual emergence analogous to the gradualist hypothesis for creolization might be valid for some of them - specifically those which have their origins in a simplified foreigner-talk variety of the lexifier language, such as Hiri Motu (Dutton 1997) but probably not for those pidgins which arose in new trade settings. In the case of abrupt pidgin genesis, the process again seems to be one of language creation rather than language 
change.

Bilingual mixed languages, finally, fall into two general categories. The one that is best understood includes Michif, Mednyj Aleut, and Media Lengua, among others, and comprises languages that arose abruptly as a marker of in-group identity. The genesis of these languages is not language change in any ordinary sense; instead, what happens is that bilingual speakers combine chunks of their two languages into a single speech form that serves some useful function in the community and therefore achieves some stability, being learned thereafter as a language by each new generation of speakers. Other bilingual mixtures, for instance Ma'a, apparently arose through gradual change, with incremental borrowing from another language that eventually overwhelms the native structures altogether. Mixed languages in this category are similar in their developmental process to creoles that arise through gradual incremental change: the end result is a mixed language that is typologically divergent from each of its source languages, but the process, at each step, is ordinary contact-induced language change.

The answer to the question of the status of mixed languages with respect to contactinduced change, then, appears to be this: the gradual development of a mixed language is unusual only in the extreme nature of the end state; the process, at every stage, is contactinduced typological change. But mixed languages - pidgins, creoles, and bilingual mixtures alike - that arise abruptly do not emerge through processes of language change at all, and they therefore are not appropriately characterized as examples of contact-induced typological change.

7. Conclusion. This article has attempted to answer the following two questions: what kinds of typological changes occur in contact situations, and under what circumstances are they likely to occur? An important theme, however, has the indeterminacy of many contact phenomena with respect to their typological impact. In particular, some contact-induced changes seem only marginally relevant to the receiving language's typological profile, so it's hard to decide whether they constitute typological change or not; and mixed languages, though certainly typologically divergent from all of their source languages, do not all arise through processes of change in a pre-existing language. One source of indeterminacy that has not been explored in any depth here is the problem of deciding whether a given change is contact-induced or not. The definition of contact-induced change given in $\S 5$ covers cases of multiple causation, where there are both internal and external causes of a particular change, but even this inclusive definition does not solve the problem entirely. As in other areas of historical linguistics (and in historical sciences in general) our lack of complete and completely reliable historical information makes indeterminacy a constant companion. 


\section{REFERENCES}

Bakker, Peter, and Robert Papen. 1997. "Michif". In: Sarah G. Thomason (ed.), Contact languages: a wider perspective (Amsterdam: John Benjamins).

Dawkins, R.M. 1916. Modern Greek in Asia Minor: a study of the dialects of Sílli, Cappadocia, and Phárasa. Cambridge: Cambridge University Press.

Comrie, Bernard. 1981. The languages of the Soviet Union. Cambridge: Cambridge University Press.

Dutton, Tom. 1997. "Hiri Motu". In: Sarah G. Thomason (ed.), Contact languages: a wider perspective (Amsterdam: John Benjamins).

Emeneau, Murray B. 1980 [1962]. "Bilingualism and structural borrowing". In: Anwar Dil (ed.), Language and linguistic area (Stanford: Stanford University Press), 38-65. Reprinted from the Proceedings of the American Philosophical Society 106.430-442 (1962).

Emeneau, Murray B. 1980 [1965]. "India and linguistic areas". In: Anwar Dil (ed.), Language and linguistic area (Stanford: Stanford University Press), 126-165. Reprinted from India and historical grammar (Annamalai University Department of Linguistics Publication No. 5), 25-75 (1965).

Fenyvesi, Anna. 1994. Language contact and language death in an immigrant language: The case of American Hungarian. Pittsburgh, PA: University of Pittsburgh M.A. thesis.

Greenberg, Joseph H. 1963. "Some universals of grammar with particular reference to the order of meaningful elements". In: Joseph H. Greenberg (ed.), Universals of Grammar (Cambridge, MA: MIT Press), 58-90.

Gumperz, John J., and Robert Wilson. 1971. "Convergence and creolization: a case from the Indo-Aryan/Dravidian border in India". In: Dell H. Hymes (ed.), Pidginization and creolization of languages (Cambridge: Cambridge University Press), 151-167.

Hetzron, Robert. 1975. "Genetic classification and Ethiopian Semitic". In: James Bynon and Theodora Bynon (eds.), Hamito-Semitica. (The Hague: Mouton), 103-127.

Leslau, Wolf. 1945. "The influence of Cushitic on the Semitic languages of Ethiopia: A problem of substratum". Word 1.59-82.

Leslau, Wolf. 1952. "The influence of Sidamo on the Ethiopic languages of Gurage". Language 28.63-81.

Li, Charles N. 1983. "Languages in contact in western China". Papers in East Asian Languages $1: 31-51$.

Menovščikov, G.A. 1969. "O nekotoryx social'nyx aspektax èvoljucii jazyka". In: Voprosy social'noj lingvistiki (Leningrad: Nauka), 110-134.

Moreno, Martino Mario. 1948. "L'azione del cuscito sul sistema morfologico delle lingue semitiche dell'Ethiopia". Rassegna di Studi Etiopici 7.121-130. 
Mous, Maarten. 1994. "Ma'a or Mbugu". In: Peter Bakker and Maarten Mous (eds.), Mixed languages (Amsterdam: Institute for Functional Research into Language and Language Use [IFOTT], University of Amsterdam), 175-200.

Muysken, Pieter. 1997. "Media Lengua". In: Sarah G. Thomason (ed.), Contact languages: a wider perspective (Amsterdam: John Benjamins).

Pfaff, Carol W. 1979. "Constraints on language mixing: intrasentential code-switching and borrowing in Spanish/English". Language 55.291-318.

Ross, Malcolm D. 1996. "Contact-induced change and the comparative method: cases from Papua New Guinea". In: Malcolm Ross and Mark Durie (eds.), The comparative method reviewed: regularity and irregularity in language change (Oxford: Oxford University Press), 180-217.

Sandalo, Filomena. 1995. A grammar of Kadiwéu. Pittsburgh, PA: University of Pittsburgh dissertation.

Silva-Corvalán, Carmen. 1994. Language contact and change: Spanish in Los Angeles. Oxford: Oxford University Press.

Thomason, Sarah Grey. 1997. "A typology of contact languages". In: Arthur K. Spears and Donald Winford (eds.), Pidgins and creoles: structure and status (Amsterdam: John Benjamins), 71-88.

Thomason, Sarah Grey, and Terrence Kaufman. 1988. Language contact, creolization, and genetic linguistics. Berkeley: University of California Press.

Thompson, Laurence C. 1979. "Salishan and the Northwest". In: Lyle Campbell and Marianne Mithun (eds.), The languages of Native America: historical and comparative assessment (Austin: University of Texas Press), 692-765. 